\title{
Challenge and Countermeasures on Application of Block Chain Technology in Library Decentralization Problem
}

\author{
Junbo Zhu \\ Xiamen University Library, Xiamen 361005, China. \\ 40712853@qq.com
}

\begin{abstract}
With the emergence of new technologies such as mobile Internet, cloud computing and big data, the means of information dissemination and information acquisition are becoming more and more diversified, and the development of libraries has shown a trend of decentralization. As a decentralized way of thinking, the application of block chain technology in libraries can completely (or partially) remove the central role of the library. On the perspective decentralization characteristics of block chain technology, this paper studies the effective combination of block chain technology and of library decentralization process. Then it analyzes the feasibility, characteristics and cases of using the block chain technology to deal with the problem of the library decentralization.
\end{abstract}

Keywords: block chain technology; library decentralization; library services; collection resource management; digital asset management.

\section{Introduction}

Decentralization is a new form of social relations formed by the development of the Internet as a catalyst compared with centralization. Its antenna extends to media, commerce, finance, urban development and many other fields. Before the rise of the Internet, libraries, with their strong resource advantages, occupied a central position in information access channels. However, with the development of the Internet, the Internet information acquisition channels represented by Google-like information search services have risen, the proportion of Libraries in information acquisition channels has declined, and the central position has disappeared. It poses a substantial challenge to the development of library cause.

As a subversive technology, the concept of block chain technology is deeply according with the characteristics of the library centralization phenomenon. Depending on the new generation of information technology such as cloud computing, internet of things, big data as infrastructure support, block chain technology will have a profound impact on the future library decentralized service model, service content and service form. The work will fully release the advantages of various agencies, and achieve deep integration across institutions, time and space. It will be providing a new impetus for the innovation and development of the library cause.

\section{The Phenomenon of Decentralization in Libraries}

Before the rise and further development of the Internet, libraries not only took on the responsibility of the center of social and cultural preservation and inheritance, but also played the role of the center of the main social information access channels [1]. For a long time, libraries have been focusing on resource construction and infrastructure construction. Influenced by the traditional concept of literature resources as the center and severely constrained by library-based thinking, the requirement of users has not been given due attention. With the wide application of mobile Internet, cloud computing, big data, Internet of Things and other emerging technologies, the information dissemination presents a new trend. With the support of information technology, the traditional media has realized digitization and networking. Books, newspapers, periodicals, dissertations, conference papers, patents, standards and other documents can be obtained through digitization and networking. On the other hand, the development of the Internet has also spawned a number of new media forms, such as blogs, micro-blogs, podcasts, forums, micro-letters and so on, known as self-media, is a new mode of communication to distinguish the mass media. Different from the mass information dissemination led by professional media organizations, since the media is the mass-led information 
dissemination activities, from the traditional "point-to-surface" dissemination into "point-to-point" peer-to-peer dissemination, information dissemination model has a very decentralized feature [2]. Users no longer obtain knowledge and information only through traditional library services. The channels and ways of information dissemination and knowledge acquisition are becoming increasingly diversified and ubiquitous. The development of libraries has shown a trend of "marginalization" and "decentralization" marked by a sharp decrease in the number of users [3]. Therefore, in the process of decentralization with globalization as the background and the Internet as the catalyst, the proportion of Libraries in the channels of information acquisition is gradually declining, and the central position of libraries as information and knowledge providers is gradually weakening. Finally, they have to face the reality of decentralization.

Decentralization of libraries is the inevitable result of the high development of the Internet and the optimization of social division of labor; the emergence of this problem can promote the industry to reflect on the basic problems of library function positioning, core value, work center, development direction, and so on, and it is also a historic opportunity for the development of libraries. In the process of de-centralization, the service mode of library has evolved from library-centered to user-centered, and the service quality and service level have also been improved [3].

\section{The Block Chain Technology and Its Implications}

Block Chain Technology is a new decentralized infrastructure and distributed computing paradigm, essentially a distributed database [4]. One of its typical applications is the digitally encrypted currency represented by Bitcoin. By means of data encryption, timestamp, consensus mechanism and incentive mechanism, the decentralized point-to-point credit transmission between nodes in distributed systems without trust is realized. Block chains have the characteristics of decentralization, sequential data, collective maintenance, programmability, security and credibility. They provide solutions to the problems of high cost, low efficiency and unsafe data storage in centralized systems. Block chains are considered to be the fifth disruptive innovation in computing paradigm after mainframes, personal computers, the Internet and mobile social networks [5]. Any area where point-to-point value transfer is required may be impacted or even reshaped by block chains technology. Online education [6], electronic health record [7] and other fields have been preliminarily explored.

Decentralization is a remarkable feature of block chain technology. It is not only an innovation, but also a development trend in the future to adopt block chain technology to deal with the phenomenon of Library decentralization. Block chain technology can effectively solve the painful points existing in the development of traditional library decentralization because of its characteristics such as unalterable, multi-center, open and free. In addition, the combination of block chain technology with large data and artificial intelligence technology can make library decentralized management more abundant and complex. In service scenarios, the application of block chain technology in Library decentralization will be more constructive in the future.

\section{The Characteristics of Block Chain Application in Library Decentralization}

Decentralization technology is the use of Distributed Accounting and storage, there is no centralized hardware or management institutions, the rights and obligations of any node are equal, the data block in the system by the maintenance function of the whole system nodes to jointly maintain, so that everyone becomes a provider of information, to solve the problem of information collection. Diversity. The large-scale use of this technology has greatly reduced the dependence of library users on the library, objectively forcing the library to change its working mode and work focus.

\subsection{Decentralization.}

Because the algorithm of block chain technology is distributed, it breaks through the centralized Central Hardware in the past and shows the characteristics that there is no central management organization. Readers and related organizations are authorized to participate in the process of library 
resources construction, knowledge services, information management and so on. In other words, the traditional library business needs to set up professional departments for centralized management, while the block chain technology will break down the library business work and allocate it to readers and social institutions, and the relevant service managers are also subject to the restriction of the equal relationship between rights and obligations. Decentralization expands the scope of library management and services, while maintaining the library decentralization application of each node, maintaining the balance and stability of the block chain system.

\subsection{Openness.}

The application of block chain technology in Library decentralization management is open. On the one hand, the library management and service system are also open, and the data layer in the block chain system is open to readers. Readers can access the library management and service system without being restricted by objective factors such as network ownership, time and space for reference, knowledge service, resource query and information acquisition. On the other hand, this openness is not absolute. For example, encrypted information related to transactions is not opened to the public. At the same time, libraries also have the responsibility to protect the private data of readers, publishers, social organizations and other library business participants to avoid the leakage of privacy [8].

\subsection{Autonomy.}

From the point of view of the application of block chain in the financial industry, block chain technology uses open and transparent data node algorithm, which produces interest system in the process of calculation and gives users certain benefits. Subject to economic factors, individuals or organizations among systems follow the principle of consensus and the system, constituting a relatively trust and free environment, in which the characteristics of autonomy derive. Combining with the "decentralization" work of the library, the application of block chain technology will follow the characteristics of autonomy, and create a relatively free and safe data exchange space for the decentralization management of the library, so that the management can achieve autonomy and independence to a certain extent, without interference from other work in the library.

\subsection{Anonymity.}

The block chain technology consensus layer adopts fixed data exchange algorithms among POW, POS, DPOS and other nodes. This algorithm pattern determines that the two sides need not be verified twice in the process of data exchange. The trust foundation of both sides has been formed, and the trust relationship is not interfered, which is based on the natural existence of the block chain technology model [9]. Because the block chain technology itself can evaluate the validity of the data exchange activities according to the rules, it saves the tedious steps such as secondary verification and information disclosure for the decentralization management of the library. Both sides of the transaction highlight the anonymity characteristics in the process of entering the business management, it also helps to maintain the high level of library management work efficiently.

\section{Case on Application of Block Chain Technology in Library Decentralization}

\subsection{An Attempt to Decentralization of Library Services.}

If the reader is regarded as a "point" and the library as a "center", then the contract for each lending process is signed between the point and the center. "Decentralization" means removing intermediaries, that is, removing the intermediate link of the library, and that books are no longer borrowed and returned through the library. "Point-to-point" is a direct transaction between readers, based on the block chain intelligent contract technology, one reader returns a book and another reader borrows the book directly linked. The circulation chain of book borrowing process is no longer interrupted by the "center" of library. In order to avoid the reader's private refusal to return books on the grounds that they are constantly borrowed by other readers, all the books that the library has borrowed need to be 
used as a database, equivalent to blocks in the block chain, in the hands of which reader, when the reader borrowed them, when they should be returned, and so on. It was found by every reader. The transfer contract between readers for book circulation is irrevocable and does not need to be confirmed by the "center" or intermediary of the library, which is the same as the block chain intelligent contract.

If such method using the block chain framework is successfully implemented, the circulation of books will be greatly enhanced. At the same time, it can enlarge the workload of librarians, greatly improve efficiency and reduce social costs. For example, completely decentralized library is actually an attempt to share books. This model is more suitable for students in the same university, allowing students to make full use of private books, but also to "book friends" to increase the exchange between students.

On the other hand, the book assets of University Libraries belong to universities, which cannot be completely separated from the library center, and the phenomenon of "incomplete decentralization" appears. For example, students must return all books borrowed before graduation, so that they can graduate. In this case, in order to ensure that graduates successfully handle the graduation procedures related to library lending, the library must have the right to prohibit the reader from lending to the next reader transfer, terminate the circulation of a Book between readers. In this way, the reader must return the book to the library after the borrowing period expires (usually one month), and the library's right to be the "center" is guaranteed.

\subsection{Application of Block Chain Technology in Library Collection Resource Management.}

Classify and store library collections. Relying on the block chain technology, such as data block and hash function, the library can classify and store the collection resources. The latest collected resources and documents can be acquired and utilized by the readers in time, while the outdated documents can be stored in the library for a long time. The library passes through the digital technology department. Rationale enables users to search and retrieve resource literature whenever and wherever possible. Block chain technology expands the sources of literature resources, facilitates the classification of library literature resources, and improves the utilization efficiency of library collection resources from the data layer.

Stable resource acquisition. Based on the characteristics of decentralization, openness, autonomy and anonymity of block chain technology and the trust environment created by block chain technology framework, the tedious steps in the process of resource construction were omitted. For example, in the process of traditional library resource management, the library purchases network resources to provide users with resource data and links. When these data are uploaded by an individual, it is necessary to extract the password when downloading, otherwise the resources cannot be obtained smoothly. Therefore, the library acts as a resource guide. Platform role, not resource provider, block chain technology breaks through this model, and integrates network resources deeply, making it a self-contained resource of Library collection. In the space of free trust in data exchange, it stabilizes the acquisition and management of library collection resources.

Open library resources management. Block chain technology has introduced new concepts and techniques into the management of library collection resources, transforming the traditional closed resource management into an open one. More readers and social organizations can participate in this process, resulting in a sense of responsibility and cohesion. From the point of view of collection resource management, it can pool ideas and expand the scope; from the point of view of the service of the whole library, it is an innovation and reform, and it can also lead the macro service concept of the library to carry out an open-ended change.

\subsection{Application of Block Chain Technology in Library Digital Asset Management.}

Modern libraries not only have traditional paper materials and books, but also with the rapid development of computer technology, network technology and hardware technology, libraries have gradually evolved from making full use of these technologies to process and store all kinds of documents with abundant pictures and texts into "digital libraries". Facing the challenge of library 
digital transformation, block chain technology has unique advantages in solving the problems related to digital asset management.

At present, users can enjoy library digital asset services through different channels. The simplest way is to open the browser to view information, customize services, search, download and other functions. Most libraries already have the ability to provide these services, and Library Digital Asset Services Based on block chain technology will be subversive and innovative. In addition to providing all the Digital Asset Services (such as basic information query, retrieval, upload, download, etc.) of the existing traditional libraries, libraries can also realize the block chain characteristic services related to digital assets by transforming the digital asset service logic into intelligent contract code.

Block chain provides a technical basis for library digital asset management, copyright protection and future library digital asset ecosystem construction by virtue of the characteristics of open and transparent data, reliable information security and traceability of sources. Library digital asset management reduces the cost of building trust through the block chain, improves the efficiency of network cooperation, accelerates the global flow of library digital asset value, and promotes the continuous evolution of the digital asset infrastructure of the next generation of libraries.

\section{Summary}

The decentralization of libraries is the inevitable result of the highly developed Internet and the optimization of social division of labor. The emergence of the problem of Library decentralization can promote the industry to reflect on the basic problems of library function positioning, core value, work center, development direction, etc. Block chain is a kind of de-centralized or point-to-point technological innovation. The application of block chain in libraries is to completely or partially remove the central role of libraries and realize the direct interaction between reader service and library construction. Using the block chain technology to deal with the problem of "de-centralization" of the library, it will comprehensively promote the upgrading of library services and management from the aspects of resources, management and service, and further promote the library cause to a new level.

\section{References}

[1]. Wang Zongyi. The Document Information Centre $\neq$ Information Consulting Service Centre[J]. Library, 2005(5):14-17, 40.

[2]. Luo Bin. Research on Internet self-media[D]. Lanzhou: Lanzhou University, 2009.

[3]. Zhou Weibing, Li Feng. Research on the formation mechanism of Library centralization under ubiquitous information environment[J]. Library work and research, 2014, 1(12):13-17.

[4]. Yuan Yong, Wang Feiyue. Development status and Prospect of block chain technology[J]. Acta Automatica Sinica, 2016, 42(4):481-494.

[5]. Swan M. Blockchain: Blueprint for a New Economy[M]. Sebastopol: O'Reilly Media, Inc, 2015: 39.

[6]. Li Qing, Zhang Xin. Block chain: promoting openness and credibility of education through technology[J]. Journal of Distance Education, 2017, 35(1):36-44.

[7]. Huang Yonggang. Safety Construction of Electronic Health Records Based on Block Chain Technology[J]. Chinese Journal of Medical Library and Information, 2016,25(10): 38-40.

[8]. Zhang Jian. The core, development and future of block chaining technology[J]. Tsinghua financial review, 2016 (5): 33-35.

[9]. Research on the Application of RFID Technology in Library Management and Service[D]. Dalian: Liaoning Normal University, 2009. 